\title{
EDITORIAL
}

\section{A molecularly guided tour along the nephron}

\author{
René J. M. Bindels
}

Published online: 18 March 2009

C The Author(s) 2009. This article is published with open access at Springerlink.com

The kidney is an intriguingly multifaceted organ controlling many vital body functions. Therefore, the kidney orchestrates a large set of tasks including the maintenance of the body fluid balance and thereby the blood pressure, the reabsorption of glucose, amino acids and other nutrients, the excretion of sodium, potassium, calcium, magnesium, and other electrolytes, and the control of the acid/base balance. In addition, the kidney produces hormones and proteins exerting important general physiological roles. For instance, the biological active form of vitamin $\mathrm{D}$ is mainly produced in the kidney through the conversion of 25 hydroxyvitamin $\mathrm{D}_{3}$ to 1,25 -dihydroxyvitamin $\mathrm{D}_{3}$ by the renal enzyme 25-hydroxyvitamin D-1- $\alpha$-hydroxylase. In addition, the antiaging hormone klotho is primarily produced in the kidney and controls overall mineral metabolism. Also, the glycoprotein erythropoietin is generated here and enhances the oxygen-carrying capacity of the blood by activating the production of erythrocytes by the bone marrow. The importance of these renal hormones is sadly demonstrated by the severe symptoms accompanying chronic kidney diseases.

The kidney is an anatomically complex structure consisting of a large number of nephrons, the functional units of the kidney. Each nephron begins with a glomerulus that filters blood entering the kidney. This filtrate then flows along the length of the nephron. The major function of the epithelial cells lining the nephron is the reabsorption of water and small molecules from the filtrate into the blood and the secretion of wastes from the blood into the urine.

R. J. M. Bindels $(\bowtie)$

Department of Physiology,

Radboud University Nijmegen Medical Center, P.O. Box 9101, 6500 HB Nijmegen, The Netherlands

e-mail: r.bindels@ncmls.ru.nl
To this end, the kidney is equipped with a host of transport proteins including ion channels, electrolyte transporters, and pumps within specific epithelial cells along the various tubule segments. In recent years, our understanding of the molecular nature of these transport proteins has made major progress through the application of functional expression cloning techniques using Xenopus laevis oocytes and the identification of gene defects in inherited renal tubular transport disorders. The regulation of these transport processes is constantly challenged by a demanding and greatly variable environment including an acidic luminal $\mathrm{pH}$, a high medullary osmolarity, and a variability in blood and urinary flow as well as in the composition of the prourine [4]. The activity of these transporters can basically be controlled at several discrete levels. First, the expression level of the particular transporter can be regulated by specific hormones. Second, trafficking of the transporter to the designated plasma membrane can be controlled by intracellular signaling processes. Third, the activity of the transport protein present at the plasma membrane can be subject to various extra-en intracellular regulatory mechanisms. Ample timely physiological studies have addressed these various regulatory aspects of renal transport processes. New key physiological mechanisms have emerged from these recent investigations particularly through a multidisciplinary approach using model cells and organisms. The complexity in structure and function of the kidney is increasingly revealed by these investigations. To do justice to this fact, a standard nomenclature has been disseminated to facilitate the renal physiologist [14]. Consequently, this special issue has been divided according to the main parts of the nephron including the proximal tubule, the loop of Henle, the distal convoluted tubule, the connecting tubule, and the collecting duct. In this guided tour along the nephron, world-renowned renal physiologists highlight the 
recent progress achieved in their particular field of renal physiology with a particular emphasis on the molecular regulation of electrolyte reabsorption processes.

The largest fraction of the glomerular filtrate is retrieved in the proximal tubule that reabsorbs among others $\mathrm{Na}^{+}$, $\mathrm{K}^{+}, \mathrm{Ca}^{2+}, \mathrm{Cl}^{-}, \mathrm{HCO}_{3}{ }^{-}, \mathrm{PO}_{4}{ }^{3-}$, glucose, amino acids, and water. The $\mathrm{Na}^{+}, \mathrm{H}^{+}$exchanger, one of the major luminal transporters, is accommodating many transport processes in this nephron segment. The molecular physiology and regulation of this exchanger is elegantly described by Bobulescu and Moe [3]. Vesicular $\mathrm{Cl}^{-} / \mathrm{H}^{+}$exchangers are expressed in the proximal tubule, and malfunction of these proteins impairs the endocytosis process in this segment explaining the primary defect in Dent's disease as outlined by Jentsch and coworkers [11]. The article by Biber et al. addresses the regulatory mechanisms controlling the activity of the $\mathrm{Na}^{+}-\mathrm{PO}_{4}{ }^{3-}$ cotransporters present in the apical membrane of the proximal tubule [2]. Finally, Verrey et al. review the transcellular amino acid transport machinery in great molecular detail illuminating the importance for overall amino acid conservation as well as for cellular housekeeping functions [16].

The loop of Henle is instrumental in the formation of concentrated or diluted urine in part by facilitating the electroneutral reabsorption of salt. The apical $\mathrm{Na}^{+}, \mathrm{K}^{+}, 2 \mathrm{Cl}^{-}$ cotransporter is the initial step in this process which is controlled by the basolateral $\mathrm{Ca}^{2+}$-sensing receptor as outlined by Gamba and Friedman [7]. As a consequence of this reabsorption process, a lumen-positive voltage is generated which drives the passive reabsorption of divalent cations through the tight junction complexes containing the claudin proteins. The role of claudins in determining the paracellular permeability in this nephron segment is the timely topic of the article by Günzel and $\mathrm{Yu}$ [8].

The final control of the electrolyte reabsorption commences in the distal convoluted tubule, a segment where the frequently subscribed thiazide diuretics exert their inhibitory effect on the $\mathrm{Na}^{+}, \mathrm{Cl}^{-}$cotransporter. This is also the major site of active $\mathrm{Mg}^{2+}$ reabsorption as illustrated by the exclusive expression of the epithelial $\mathrm{Mg}^{2+}$ channel TRPM6 and reviewed by Xi et al. in this special issue [19].

The article by Boros and colleagues provides recent developments in the physiology of active $\mathrm{Ca}^{2+}$ reabsorption as it takes place in the late distal convoluted and connecting tubule [5]. This latter segment also houses the epithelial $\mathrm{Na}^{+}$channel, ENaC, that constitutes the rate-limiting step of transepithelial $\mathrm{Na}^{+}$reabsorption and is the main target of hormones like aldosterone and vasopressin. Loffing and Korbmacher, both experts in this field, elegantly review the regulation of $\mathrm{Na}^{+}$transport in this connecting segment [9].

Moving along the nephron, Wagner et al. discuss the ins and outs of acid-base transport in the collecting duct [17]. Notably, the connecting tubule and the adjacent collecting duct are not only composed of principal cells but also contain intercalated cells that play indeed an important role in the acid-base homeostasis. Both cell types are, however, also key players in the final regulation of the renal $\mathrm{K}^{+}$ excretion. Wang and Giebisch highlight in detail the various $\mathrm{K}^{+}$transport proteins and their regulation in this part of the nephron [18]. Vasopressin-regulated urea transport in the collecting duct contributes to the ability of the kidney to form highly concentrated urine during antidiuresis. To date, several urea transporters have been cloned from the kidney, and their physiological relevance has been demonstrated using various knockout mouse models as reviewed by Fenton in this special issue of Pflügers Archiv [6]. Malfunction of primary cilia presents among others in this part of the nephron has been associated with polycystic kidney disease. The primary cilium is present in every epithelial cell lining the renal tubule and is fundamental for a normal tubule organization and function. Here, RodatDespoix and Delmas extensively review the intriguing function of these versatile mechano- and chemosensors in the nephron [12].

Renal physiology is regularly studied at the level of the nephron, the epithelial cell, or the individual proteins [1]. Over the years, specific techniques have been developed which specifically reveal the intriguing physiological functions of the kidney at the various levels. This special issue would not be complete without the reference to the most dedicated and appealing techniques. Instrumental for the renal physiologists is the micropuncture technique to directly access the superficial nephrons in vivo. Vallon, one of the few micropuncture experts, shares his experiences with this technique and shows how the application of this technique can further advance our knowledge of kidney physiology [15]. New microscopy and imaging techniques are increasingly applied to study the function of the kidney and derived cells hereof. Molitoris and Sandoval highlight the latest advancements to dynamically study renal transport processes, including the use of two-photon microscopy and the application of multiple fluorophores [10]. Generation of transgenic animal models has, in general, greatly advanced our physiological knowledge. Recent developments allow kidney and even nephron segment-specific gene targeting and ablation in mice which opens a new area to study the physiological processes of electrolyte handling in health and disease as sophisticatedly discussed by Rubera and colleagues [13].

In summary, this special issue bundles distinguished contributions in diverse fields of renal physiology and will hopefully further stimulate researchers to discuss and investigate the mechanisms of electrolyte transport. Comprising these mechanisms will be essential to our understanding of mammalian kidney physiology in general. 
Open Access This article is distributed under the terms of the Creative Commons Attribution Noncommercial License which permits any noncommercial use, distribution, and reproduction in any medium, provided the original author(s) and source are credited.

\section{References}

1. Bens M, Vandewalle A (2008) Cell models for studying renal physiology. Pflugers Arch 457:1-15

2. Biber J, Hernando N, Forster I, Murer H (2008) Regulation of phosphate transport in proximal tubules. Pflugers Arch, in press

3. Bobulescu IA, Moe OW (2008) Luminal $\mathrm{Na}^{+} / \mathrm{H}^{+}$exchange in the proximal tubule. Pflugers Arch, this issue

4. Boone M, Deen PM (2008) Physiology and pathophysiology of the vasopressin-regulated renal water reabsorption. Pflugers Arch 456:1005-1024

5. Boros S, Bindels RJ, Hoenderop JG (2008) Active $\mathrm{Ca}^{2+}$ reabsorption in the connecting tubule. Pflugers Arch, this issue

6. Fenton RA (2008) Essential role of vasopressin-regulated urea transport processes in the mammalian kidney. Pflugers Arch, this issue

7. Gamba G, Friedman PA (2008) Thick ascending limb: the $\mathrm{Na}^{+}$: $\mathrm{K}^{+}: 2 \mathrm{Cl}^{-}$co-transporter, NKCC2, and the calcium-sensing receptor, CaSR. Pflugers Arch, this issue
8. Gunzel D, Yu AS (2008) Function and regulation of claudins in the thick ascending limb of Henle. Pflugers Arch, this issue

9. Loffing J, Korbmacher C (2009) Regulation of sodium transport in the connecting tubule. Pflugers Arch, this issue

10. Molitoris BA, Sandoval RM (2009) Techniques to study nephron function: microscopy and imaging. Pflugers Arch, this issue

11. Plans V, Rickheit G, Jentsch TJ (2008) Physiological roles of CLC $\mathrm{Cl}^{-} / \mathrm{H}^{+}$exchangers in renal proximal tubules. Pflugers Arch, this issue

12. Rodat-Despoix L, Delmas P (2009) Ciliar functions in the nephron. Pflugers Arch, this issue

13. Rubera I, Hummler E, Beermann F (2008) Transgenic mice and their impact on kidney research. Pflugers Arch, this issue

14. The Renal Commission of the International Union of Physiological Sciences (IUPS) (1988) A standard nomenclature for structures of the kidney. Pflugers Arch 411:113-120

15. Vallon V (2008) Micropuncturing the nephron. Pflugers Arch, this issue

16. Verrey F, Singer D, Ramadan T, Vuille-Dit-Bille RN, Mariotta L, Camargo SM (2009) Kidney amino acid transport. Pflugers Arch, this issue

17. Wagner CA, Devuyst O, Bourgeois S, Mohebbi N (2009) Regulated acid-base transport in the collecting duct. Pflugers Arch, this issue

18. Wang WH, Giebisch G (2008) Regulation of potassium (K) handling in the renal collecting duct. Pflugers Arch, in press

19. Xi Q, Hoenderop JG, Bindels RJ (2008) Regulation of magnesium reabsorption in DCT. Pflugers Arch, this issue 